\title{
Statistical Method for Determining the Levelness Parameters of Different Coloured Polymeric Fabrics
}

\author{
S.F. Ibrahim (Corresponding author), D.M.Essa \& E.M.Osman \\ Textile Department Division, National, Institute for Standards \\ Tersa St., El-Haram, Giza, Egypt
}

Tel: 20-237-401-113Ｅ-mail: drsaherfawzy09@hotmail.com

Received: December 14, 2010 Accepted: December 28, 2010 doi:10.5539/ijc.v3n3p11

\begin{abstract}
In this research work an objective method for evaluating the levelness (L) of coloured textile materials by spectrophotometric measurements is reported. Colour levelness is actually a description of the uniformity of colour shade in different places of the fabric. Thus, we use three different fabrics namely, wool, polyester and wool/polyester blend $(65 / 35 \%)$, firstly these fabrics are treated with different uv/ozone exposure times continued for one hour exposure, followed by dyeing separately with three different dye classes; reactive, direct and acid. The colour strength $(\mathrm{K} / \mathrm{S})$ and colour difference $\Delta \mathrm{E}$ after exposing of the treated dyed samples to artificial day light are measured spectrophoto-metrically. The results of these measurements are statistically correlated with the levelness (L), relative standard deviation $\operatorname{Sr}(\lambda)$, and the unlevelness (U). The obtained results showed that the dyeability, $\mathrm{L}$ parameter, $\mathrm{U}$ parameter and $\Delta \mathrm{E}$ values are greatly depend on the dye class used, fabric nature, and type of treatment applied. Where as these parameters reflect the effect of homogeneity of dye distribution on the fabric which decreases the colour fading of the dyed samples under test. Where uv/ozone exposure leads to the increase in the amorphousity of the exposed samples especially at the end of exposure leading to an increase in the exhaustion and diffusion of the dye inside the fabric pores besides, to its effect on districting the dye accumulation and hence increases the levelness of dyeing.
\end{abstract}

Keywords: Fabrics, Dyes, Colour levelness (L), Relative Standard Deviation $\operatorname{Sr}(\lambda), \mathrm{K} / \mathrm{S}$, Colour difference $\Delta \mathrm{E}$, uv/ozone treatment

\section{Introduction}

Textile manufacturing industries are mainly concerned with the appearance of colour uniformity in terms of levelness parameters in dyed fabrics and/or a union shade in dyed fabrics of more than one fiber type (Yang Y., \& Shiqi, L., 1993). Colour quality, rather than uniformity, is traditionally measured by colourimetric methods that rely on measurement systems, such as the CIELAB from the Commission International de L'eclairage that employs lightness $\left(\mathrm{L}^{*}\right)$, redness or greenness $\left(\mathrm{a}^{*}\right)$ and yellowness or blueness $\left(\mathrm{b}^{*}\right)$ measurements (Christie, R.M., et.al. 2000).

\subsection{Levelness Parameters}

The differences among K/S values obtained from different areas of a piece of fabric can be used to evaluate the color levelness. These differences can be included in the sample standard deviation of a $\mathrm{K} / \mathrm{S}$ value at a certain wavelength $(\lambda)$;

$$
\mathrm{S}(\lambda)=\sqrt{\frac{\sum_{i=1}^{n}[(K \backslash S) i, \lambda-\overline{(K \backslash S) \lambda}]^{2}}{n-1}}
$$

Where $\lambda=$ wavelength of the measurement, $\mathrm{n}=$ total number of measurements,

$(\mathrm{K} / \mathrm{S}) \mathrm{i}, \lambda=\mathrm{K} / \mathrm{S}$ value of $\mathrm{i}$ the measurement at $\lambda$, and:

$$
\overline{(K \backslash S) \lambda}=\frac{1}{n} \sum_{i=1}^{n}(K \backslash S) i, \lambda
$$

The magnitude of $S(\lambda)$ is not only a function of the difference of $\mathrm{K} / \mathrm{S}$ values from different places of the fabric, 
but also a function of the average $\mathrm{K} / \mathrm{S}$ value of that fabric. The absolute difference between $(\mathrm{K} / \mathrm{S})_{\lambda}$ and $(\mathrm{K} / \mathrm{S})_{\lambda}$ is large with a larger $(\mathrm{K} / \mathrm{S})_{\lambda}$. Therefore, a relative value of the sample standard deviation, $\operatorname{Sr}(\lambda)$ is necessary to compare the L of two pieces of fabrics with different K/S (Smith, 1985 \& Janos, S., 2007.), as mentioned from the following equation;

$$
\mathrm{S}_{\mathrm{r}}(\lambda)=\sqrt{\frac{\sum_{i=1}^{n}\left[\frac{(K \backslash S) i, \lambda}{\overline{(K \backslash S) \lambda}}-1\right]^{2}}{n-1}}
$$

Since human sensitivity to different wavelengths is different from that of the instrument, $\operatorname{Sr}(\lambda)$ should be adjusted by spectral luminous function [V $(\lambda)]$. This adjustment relates to the visual observation and hence the unlevelness parameter $\mathrm{U}(\lambda)$ can be calculated from the equation:

$$
\mathrm{U}=\sum_{\lambda=400}^{700} S_{r}(\lambda) V(\lambda)
$$

Where, a larger $\mathrm{U}(\lambda)$ means that the $\mathrm{L}$ of the colored textile is poorer. The luminous efficiency function $[\mathrm{V}(\lambda)]$; a dimensionless function, is used to describe the change of relative spectral sensitivity with wavelength by adjusting the maximum luminous efficiency to 1.0 (Wyszeck, G. \& Stiles, W. S. 1982).

Although the $\mathrm{U}$ value can be used to evaluate and characterize the levelness of textiles with different colors and $\mathrm{K} / \mathrm{S}$, its value is not as sensitive to the material with high and low color levelness. Hence, the L parameter gives better proportional agreement with actual levelness increments (Smith, 1985, ISO 23539/CIE Solo: 2005).

$$
\mathrm{L}=1.20\left[2.00-\ln \sum_{\lambda=400}^{700} S_{r}(\lambda) V(\lambda)\right]
$$

Where 1.20 and 2.00 are constants which adjust the value. Thus, larger $L$ values result in better levelness of the coloration.

\subsection{Color Difference ( $\Delta E$ )}

The human eye can detect small differences in color, but it is difficult to quantify color differences accurately. Instrumental measurements can overcome this problem by using modern instruments that are able to measure tristimulus values accurately and reproducibly, and the $\Delta \mathrm{E}$ (equation 6) is used, the function of which is to provide a single number which is more precise and nearly equivalent to the grade of the visual difference between different colors (Christie, R.M., et.al., 2000).

$$
\Delta \mathrm{E}=\sqrt{\left[(\Delta L *)^{2}+(\Delta a *)^{2}+(\Delta b *)^{2}\right]}
$$

$\Delta \mathrm{L}^{*}=\mathrm{L}^{*}$ sample $-\mathrm{L}^{*}$ standard, $\Delta \mathrm{a}^{*}=\mathrm{a}^{*}$ sample $-\mathrm{a}^{*}$ standard, $\Delta \mathrm{b}^{*}=\mathrm{b}^{*}$ sample $-\mathrm{b}^{*}$ standard

Where: standard refers to the dyed fabric; sample refers to the dyed sample after exposure to artificial day light.

\section{Experimental Work}

\subsection{Materials and Chemicals}

2.1.1 Fabrics; the used fabrics were:

- $\quad$ Pure wool fabrics (100\%), weight $130 \mathrm{~g} / \mathrm{m}^{2}$, thickness $0.348 \mathrm{~mm}$,

- $\quad$ Pure polyester fabrics (100\%), weight $134 \mathrm{~g} / \mathrm{m}^{2}$, thickness $0.366 \mathrm{~mm}$,

- $\quad$ Blend (wool/ polyester 65/35\%) fabrics, weight $143.78 \mathrm{~g} / \mathrm{m}^{2}$, thickness $0.384 \mathrm{~mm}$.

These fabrics were kindly supplied by Golden Tex Company, Egypt, and purified in a laboratory by scouring with a solution containing $2 \mathrm{~g} / \mathrm{L}$ of non-ionic detergent using a liquor ratio $1: 50$ at temperature $60{ }^{\circ} \mathrm{C}$ for 15 minutes. Finally, the samples were thoroughly washed with tap water and dried at ambient conditions (Michael, M.N., et al., 2004).

\subsubsection{Dye-classes}

The following dye classes were used: 
1-Reactive dye: Primazine brilliant violet RL, C.I. Reactive Violet B-E 20, (Basf Company) based on an acryloamide reactive group: (-NH-CO-CH= $\mathrm{CH}_{2}$ ).

2-Direct dye: Solophenyl Orange TGl 182\%, C.I. Direct Orange 108, (Bayer Company).

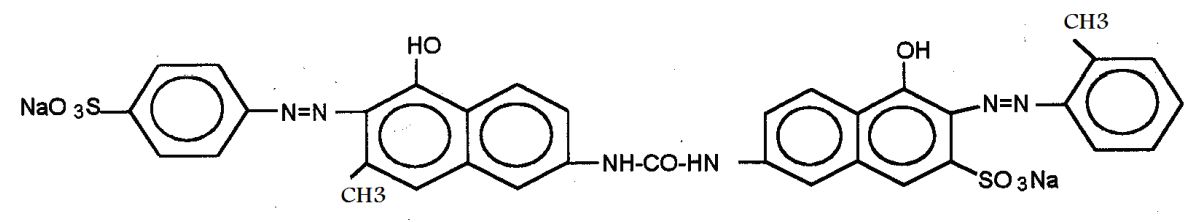

Direct Orange108

3)-Acid dye: Fluorescent Yellow RXL, C.I. Acid Yellow 117) (Clarinet Company).

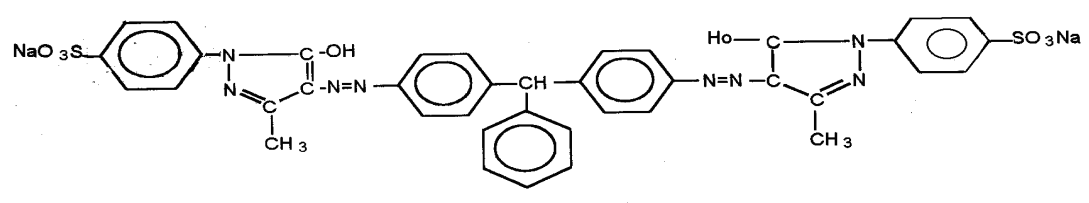

Acid Yellow 117

\subsection{UV/Ozone Treatment (Robert, M. S. \& Francis, X.W. 1996)}

All samples under test in the form of strips were exposed to uv/ozone source for different periods $(1,3,5,10,15$, 20, and 60 minutes). Where, high intensity, low-pressure mercury lamp without outer envelope -LRF 02971, 200 watt, 220 volt, made in Poland- was placed in a cubic box with side length $60-\mathrm{cm}$. The samples were put around the source at a distance $20 \mathrm{~cm}$. Atomic oxygen is generated both when molecular oxygen is subjected to the $184.9 \mathrm{~nm}$ radiation and when ozone is irradiated at $253.7 \mathrm{~nm}$. The $253.7 \mathrm{~nm}$ radiation is absorbed by most hydrocarbons and also by ozone (Michael, M. N., et. al., 2004).

\subsection{Dyeing, Testing and Analysis;}

\subsubsection{Dyeing Method;}

The unexposed and exposed samples for different uv/ozone exposure times (1, 3, 5, 10, 15, 20 and 60 minutes) were separately dyed by each of the above mentioned three dyes in a laboratory dyeing apparatus using the conventional exhaustion dyeing method' where a fixed dye concentration of $2 \mathrm{~g} / \mathrm{L}$ was used. All dyeings were carried out at temperature $80{ }^{\circ} \mathrm{C}$ for half an hour with a liquor ratio of 1:100.The dyed samples were thoroughly washed, and finally dried at ambient conditions (Garland, 1983).

\subsubsection{Colour Strength $(\mathrm{K} / \mathrm{S})$ and Colour Difference $(\Delta \mathrm{E})$ Determination}

The spectrophotometer used for measuring the $\mathrm{K} / \mathrm{S}$ and $\Delta \mathrm{E}$ of all the dyed samples is the Optimatch $3100 \AA$ from the SDL Company. All the dyed samples were measured in a visible region, i.e., a wavelength range from $400-700 \mathrm{~nm}$, with an interval of $10 \mathrm{~nm}$. The mean value of the 10 readings was taken for each sample (Yang Y. \& Shiqi L., 1993). The colour difference $\Delta \mathrm{E}$ values were calculated between the artificial light exposed and unexposed dyed samples were determined as previously mentioned, according to equation (6).

\section{Results and Discussion}

Tables (1-3) show the comparison of some levelness parameters $(\Sigma \mathrm{Sr}(\lambda), \mathrm{L}$, and $\mathrm{U}(\lambda)$, for the three different fabrics under investigation namely, wool, polyester and wool/polyester blend. Firstly, these fabrics are treated with different uv/ozone exposure times followed by dyeing separately with the following dye classes that have three different colours: C.I. Reactive Violet B-E 20, C.I. Direct Orange 108, and C.I. Acid Yellow 117. The data of $\Sigma \operatorname{Sr}(\lambda)$ - derived from equation 3- are necessary to compare the levelness parameters of the tested fabrics with different $(\mathrm{K} / \mathrm{S})$ and can be adjusted by the calculation of spectral luminous function $[\mathrm{V}(\lambda)]$ that is used to obtain a clear trend for the dye distribution on the fabrics, i.e., the un-levelness that refers to the non-homogeneity of the colour distribution on the fabrics which is inversely related to homogeneity of the dye distribution on the fabric i.e., L- values. It is clear that, there are many factors affecting the dye distribution on the fabric and consequently its homogeneity, including uv/ozone exposure times, fabric type and dye class used.

The results predicted in tables (1-3) showed that for blank fabrics dyed separately with direct and reactive dye both the dye-ability (K/S) and the levelness parameter values follow the order: wool > blend (wool / polyester) > 
polyester, and the reverse trend is observed for their corresponding un-levelness values. While for acid dye the trend is: blend (wool / polyester) > wool > polyester. These results reflect the homogeneity of dye distribution on the fabric which decreases the colour fading of the dyed samples under test. The mutual order for the wool / polyester blended fabric is due to the fact that they can be considered as a hybrid structures of wool and polyester fabrics blended together to form a system, the differences in their contributions towards the overall behaviour follows the rule - of- mixture behaviour, that is, the resultant properties of the structure are the mean values of the volume fraction weighted properties of its constituents. Although, in critical cases there are deviations from this rule, where, the strength of a blended fabric can be lower or higher than the strength of its constituents (Ibrahim, S. F., Ph.D. Thesis, 2003).

On considering the effect of uv/ozone exposure on the homogeneity of dye distribution for the fabrics, the results that represented through figures (1-3) show that for all samples increasing treatment time increase both of the $\mathrm{K} / \mathrm{S}$ and the levelness $\mathrm{L}$ values while the non-homogeneity $U$ values decrease. The highest observed increase in dye-ability and levelness that obtained by prolonging uv/ozone exposure, depends mainly on the fabric type and its chemical structure. Thus the following trend was observed for both $\mathrm{K} / \mathrm{S}$ and levelness $\mathrm{L}$ values: wool > blend $>$ polyester regardless of the dye type which is the reverse trend of un-levelness (U). The observed improvement in $(\mathrm{K} / \mathrm{S})$ and $(\mathrm{L})$ values of wool fabrics by prolonging uv/ozone exposure could be explained in view of the previously discussed results by many authors [Hawkyard, C. J., et al. 1997, Michael, M. N., et al 2004 \& Ibrahim, S. F., Ph.D. Thesis, 2003) who showed that uv/ozone exposure decreased the crystallinity / amorphousity ratio, in the majority of exposure periods and its effect in increasing the intensity of the different functional groups in the pretreated fabrics (Ibrahim, S. F., Ph.D. Thesis, 2003). The increase in the amorphousity especially at the end of exposure leading to an increase in the exhaustion and diffusion of the dye inside the fabric pores whereas; uv/ozone exposure of the samples districts the dye accumulation and hence increases the levelness of dyeing. For polyester fabric the observed slight increase in $(\mathrm{K} / \mathrm{S})$ and $(\mathrm{L})$ values by prolonging uv/ozone exposure, is due to the increase in the polarity of these treated fabrics, which results from the increase in the intensity of different functional groups of these fabrics by prolonging exposure to uv/ozone leading to an increase in their availability for linkage with the reactive species of each dye applied, and hence increasing dye up-take but to an extent depends on the dye type (Bhama Iyer P., et al., 1976). While the improvement in (K/S) and (L) values by prolonging uv/ozone exposure of blend (wool/polyester) fabrics especially at the end of exposure, can be explained in view of the fact that (Ibrahim, S. F., Ph.D. Thesis, 2003), there is a remarkable increase in the peak intensity values of the different functional groups which characterize such blend especially at the end of exposure. This results in increasing the dipole moment of such treated blended fabrics, leading to encouraging the attraction, exhaustion and diffusion of the dye molecules to the fabric surface (Tera, F. M., et al., 1987). Also, the observed behaviour of this blend can be explained in view of the rule of mixture behavoiur as we stated above.

On considering the effect of the nature and characteristics of the different dye class used on the percentage improvement of the levelness at the end of the treatment (60 minutes) -- each was calculated relative to its initial value -- the following orders are observed:

For wool fabric:

Acid dye $(34.3 \%)>$ direct dye $(26.41 \%)>$ reactive dye $(24.5 \%)$

For polyester fabric:

Acid dye $(40.9 \%)>$ reactive dye $(38.9 \%)>$ direct dye $(30.7 \%)$

For blend fabric:

Direct dye $(132 \%)>$ reactive dye $(19.7 \%)>$ acid dye $(10.9 \%)$

The results of the levelness parameters are manifested by measuring the colour difference $\Delta \mathrm{E}$ values (figures 4-6) which are taken as (Gulrajani \& Gupta, 1993) the difference between the $(\Delta \mathrm{E})$ values of uv/ozone treated dyed samples and their corresponding $(\Delta \mathrm{E})$ of samples exposed to artificial day light. Whereas these values give a precise and accurate estimation of the fastness of coloured light exposed fabrics. Generally, the colour difference decrease by treatment and reaching maximum decrease at the end of the treatment (60 minutes).These results agree well with the obtained L-values and inversely proportional to unlevelness parameter. This means that the highest the levelness the lowest $\Delta \mathrm{E}$ values, on other words, homogenous distribution of the dye on fabric renders the dye more tightly adhered to the fabrics, while non homogenous distribution of the dye, means that, the highest the $\mathrm{U}$ values the highest $\Delta \mathrm{E}$ values, i.e., the dye easily faded by exposure (Mclaren, 1983 \& Harod, R.W. 1989). On comparing $\Delta \mathrm{E}$ values (tables I-III) of the examined samples at the end of the treatment, the following 
orders are observed:

On using direct dye:

$(\Delta E)$ of blend (lowest negative value) $>(\Delta E)$ of polyester $>(\Delta E)$ of wool

On using acid dye:

$(\Delta \mathrm{E})$ of polyester (lowest negative value) $>(\Delta \mathrm{E})$ of wool $>(\Delta \mathrm{E})$ of blend.

On using reactive dye:

$(\Delta \mathrm{E})$ of polyester (lowest negative value) $>(\Delta \mathrm{E})$ of blend $>(\Delta \mathrm{E})$ of wool.

This supports the last obtained levelness results which can be interpreted mainly by the homogeneity of the dye distribution on these treated fabrics. From the result obtained on this research work we can conclude that the dyeability $(\mathrm{K} / \mathrm{S})$, levelness $\mathrm{L}$ parameter, unlevelness $\mathrm{U}$ parameter and colour difference $\Delta \mathrm{E}$ values are greatly depend on the dye type, fabric nature, and type of treatment. Where, higher $\mathrm{K} / \mathrm{S}$ and $\mathrm{U}$, i.e. non homogenous distribution of dye particles, lead to larger sized aggregated dye particles, so they can not easily fade by light exposure (i.e. smaller $\Delta \mathrm{E}$, higher light fastness). Lower $\mathrm{K} / \mathrm{S}$ and $\mathrm{U}$ values, i.e. higher $\mathrm{L}$ and $\Delta \mathrm{E}$ values, (homogenous distribution of dye particles) where the dye can be considered either as mono-dispersed or aggregated with smaller particle size, so they can be easily faded on exposure i.e., lower fastness obtained (Mclaren, 1983 \& Harod R. W., 1989).

\section{Conclusion}

The results obtained by studying $\mathrm{L}, \mathrm{U}$ and their relation to $\Delta \mathrm{E}$ using three different dye classes on three different fabrics (wool, polyester and wool/polyester blend) at different uv/ozone exposure times showed that; there are many factors affecting the dye distribution on the fabric and consequently its homogeneity, including; uv/ozone exposure times, fabric type and dye class used. Where; for blank fabrics dyed separately with direct and reactive dye both the dye-ability (K/S) and the levelness parameter values follow the order: wool $>$ blend $>$ polyester and the reverse trend is observed for the un-levelness value. While for acid dye the trend is: blend $>$ wool $>$ polyester. The results showed that by prolonging uv/ozone exposure the levelness increase with increasing the K/S values for all fabrics under investigation and the percentage increase in dye-ability $(\mathrm{K} / \mathrm{S})$ reached maximum values at the end of treatment. Both of the nature and characteristics of the different dye class used are largely affect on the percentage improvement of the levelness at the end of the treatment where, the recorded orders are: for wool fabric: acid dye $>$ direct dye $>$ reactive dye, for polyester fabric: acid dye $>$ reactive dye $>$ direct dye, and for blended fabric: direct dye $>$ reactive dye $>$ acid dye. Finally, we can conclude that the dyeability (K/S), L parameter, $\mathrm{U}$ parameter and $\Delta \mathrm{E}$ values are greatly depend on the dye type, fabric nature, and type of treatment applied.

\section{References}

Bhama Iyer P., Krishna Iyer, K.R. \& Patil, N.B. (1976). An Infrared Technique for the Quick Analysis of Cotton -Polyester Blends, Journal of Applied Polymer Science, vol. 20, pp. 59-595.

Christie, R.M., Mather, R.R. \& Wardman, R.H. (2000). The Chemistry of Colour Application, Blackwell Science Ltd., USA.

Giles, C.H., Datner, A., Duff, D.G., Sinclair, R.S. \& Stens, C.B. (1974). A Laboratory Course of Dyeing, Society of Dyers and Colourists., Third Edition. Bradford, Yorkshire.

Gulrajani, M.L. \& Gupta, D.B. (1993). Natural Dyes and their application to textiles, Raj Kamal Electric Press, New Delhi.

Harod, R.W. (1989). Experiment, 3, Developing Specimen Measurement Repeatability, Color measurement Committee Meeting, Charlotte, N.C.

Hawkyard, C.J., Shao, J., \& Carr, C.M. (1997). 'Investigation Into the Effect of UV/ozone Treatments on Dye-ability and Printability of Wool', Journal Society of Dyers and Colourists, vol. 113, pp. 126-130.

Ibrahim, S. F., Ph.D. Thesis. (2003). Investigation into the Effect of uv/ozone Treatments on the Physical Properties and Dyeing Kinetics of some Polymeric Fabrics, Faculty of Science, Cairo University.

ISO 23539/CIE Solo. (2005). Photometry - The CIE System of physical Photometry.

Janos, S. (2007). University of Pannonia, Hungary (Colourimetry under Standing the CIE System), A JOHN WIEY \& SONS, INC., Publication.

Mclaren, K. (1983). The colour science of dyes and pigments, Adam Hilger Ltd., Bristol, pp. 62. 
Michael, M.N., El-Zaher, N.A., \& Ibrahim, S.F. (2004). Investigation into Surface Modification of some Polymeric Fabrics by uv/ozone Treatment, Polymer-Plastics Technology and Engineering, vol. 43, pp. 1041-1052.

Robert, M. S. \& Francis, X.W. (1996). Spectrometric Identification of Organic Compounds, Sixth Edition, vol. 27, no. 12 .

Smith, G. (1985). Statistical Reasoning, Allyn and Bacon, Boston, Mass. Wyszeck, G. \& Stiles, W.S. 1982, 'Colour Science', 2nd edition, John Wiley \& Sons, New York, N.Y.

Tera, F.M., Hebeish, A. \& Micheal, M.N. (1987). Spectropfotometric Study of the Photo-degradation of Disperse Dyes on Cellulose Diacetate and Polyamde Films, Journal of Polymer Degradation and Stability, vol. 17.

Wyszeck, G. \& Stiles, W.S. (1982). Colour Science, 2nd edition, John Wiley\& Sons, New York, N.Y.

Yang, Yiqi; Li, Shiqi. (1993). Instrumental measurement of the levelness of textile colouration. Textile Chemist and Colorist, 25 (9), 75-78.

Table 1. Effect of different uv/ozone treatment times on $(\mathrm{K} / \mathrm{S}$, levelness parameters and $\Delta \mathrm{E})$ values of the examined samples dyed with acid dye.

\begin{tabular}{|c|c|c|c|c|c|c|c|c|c|c|c|c|c|c|c|}
\hline \multirow[b]{2}{*}{$\begin{array}{c}\text { exposure } \\
\text { time } \\
\text { (mins.) }\end{array}$} & \multicolumn{5}{|c|}{ Wool } & \multicolumn{5}{|c|}{ polyester } & \multicolumn{5}{|c|}{ wool/polyester blend } \\
\hline & $\mathrm{K} / \mathrm{S}$ & $\begin{array}{c}\sum \mathrm{Sr} \\
(\lambda)\end{array}$ & $\mathrm{L}$ & U & $(\Delta \mathrm{E})^{*}$ & $\mathrm{~K} / \mathrm{S}$ & $\begin{array}{c}\sum \mathrm{Sr} \\
(\lambda)\end{array}$ & $\mathrm{L}$ & $\mathrm{U}$ & $(\Delta \mathrm{E})^{*}$ & $\mathrm{~K} / \mathrm{S}$ & $\begin{array}{c}\sum \mathrm{Sr} \\
(\lambda)\end{array}$ & $\mathrm{L}$ & $\mathrm{U}$ & $(\Delta \mathrm{E})^{*}$ \\
\hline 0 & 20.657 & 0.039 & 4.455 & 0.181 & 0 & 0.331 & 0.037 & 4.046 & 0.254 & 0 & 2.961 & 0.033 & 5.395 & 0.082 & 0 \\
\hline 1 & 21.333 & 0.039 & 4.643 & 0.154 & -0.39 & 0.341 & 0.036 & 4.359 & 0.195 & -0.22 & 2.980 & 0.014 & 1.969 & 1.432 & -0.93 \\
\hline 3 & 22.707 & 0.036 & 4.779 & 0.138 & -1.49 & 0.346 & 0.032 & 4.759 & 0.140 & -0.65 & 3.370 & 0.025 & 3.287 & 0.498 & -1.52 \\
\hline 5 & 23.520 & 0.041 & 4.929 & 0.127 & -2.43 & 0.394 & 0.085 & 5.032 & 0.112 & -1.18 & 3.670 & 0.035 & 5.367 & 0.084 & -3.03 \\
\hline 10 & 24.178 & 0.042 & 5.026 & 0.112 & -3.81 & 0.431 & 0.316 & 5.362 & 0.085 & -1.33 & 4.880 & 0.035 & 5.586 & 0.070 & -3.58 \\
\hline 15 & 25.372 & 0.049 & 5.407 & 0.099 & -5.56 & 0.448 & 1.169 & 5.453 & 0.079 & -1.65 & 5.580 & 0.036 & 5.463 & 0.078 & -3.86 \\
\hline 20 & 26.021 & 0.141 & 5.775 & 0.078 & -8.56 & 0.548 & 1.657 & 5.521 & 0.074 & -2.14 & 5.690 & 0.035 & 5.617 & 0.069 & -3.87 \\
\hline 60 & 28.022 & 0.042 & 5.983 & 0.051 & -19.49 & 0.583 & 0.939 & 5.699 & 0.064 & -2.20 & 8.950 & 0.034 & 5.978 & 0.051 & -4.49 \\
\hline
\end{tabular}

*note / The negative values of colour difference $\Delta \mathrm{E}$ explained as they were taken as the difference between the $\Delta \mathrm{E}$ values of uv/ozone treated dyed samples unexposed to artificial light of smaller value $\mathrm{X}$ and their correspondings $\Delta \mathrm{E}$ of these samples exposed to artificial day light of larger value $\mathrm{Y}$ thus the calculated $\Delta \mathrm{E}$ in the table $=(\mathrm{X}-\mathrm{Y}$ might be negative $)$. 
Table 2. Effect of different uv/ozone treatment times on (K/S, levelness parameters and $\Delta \mathrm{E})$ values of the examined samples dyed with direct dye.

\begin{tabular}{|c|c|c|c|c|c|c|c|c|c|c|c|c|c|c|c|}
\hline \multirow[b]{2}{*}{$\begin{array}{c}\text { exposure } \\
\text { time } \\
\text { (mins.) }\end{array}$} & \multicolumn{5}{|c|}{ Wool } & \multicolumn{5}{|c|}{ polyester } & \multicolumn{5}{|c|}{ wool/polyester blend } \\
\hline & $\mathrm{K} / \mathrm{S}$ & $\begin{array}{c}\sum \mathrm{Sr} \\
(\lambda)\end{array}$ & $\mathrm{L}$ & $\mathrm{U}$ & $(\Delta \mathrm{E})^{*}$ & $\mathrm{~K} / \mathrm{S}$ & $\begin{array}{c}\sum \mathrm{Sr} \\
(\lambda)\end{array}$ & $\mathrm{L}$ & U & $(\Delta \mathrm{E})^{*}$ & $\mathrm{~K} / \mathrm{S}$ & $\begin{array}{c}\sum \mathrm{Sr} \\
(\lambda)\end{array}$ & $\mathrm{L}$ & $\mathrm{U}$ & $(\Delta \mathrm{E})^{*}$ \\
\hline 0 & 1.942 & 0.171 & 5.418 & 0.081 & 0 & 1.1501 & 0.032 & 5.509 & 0.226 & 0 & 0.673 & 0.032 & 2.637 & 0.045 & 0 \\
\hline 1 & 2.523 & 0.077 & 5.776 & 0.060 & -0.46 & 1.174 & 0.032 & 5.556 & 0.157 & -1.37 & 0.684 & 0.035 & 3.477 & 0.054 & -4.29 \\
\hline 3 & 2.669 & 0.045 & 6.221 & 0.041 & -2.47 & 1.1993 & 0.033 & 5.697 & 0.080 & -1.97 & 0.759 & 0.034 & 4.162 & 0.053 & -4.34 \\
\hline 5 & 3.080 & 0.045 & 6.267 & 0.039 & -3.29 & 1.204 & 0.0398 & 5.846 & 0.075 & -2.87 & 0.762 & 0.044 & 5.331 & 0.087 & -5.25 \\
\hline 10 & 4.047 & 0.037 & 6.284 & 0.039 & -3.41 & 1.254 & 0.258 & 5.938 & 0.072 & -2.98 & 0.794 & 0.034 & 5.868 & 0.052 & -5.47 \\
\hline 15 & 6.820 & 0.035 & 6.579 & 0.038 & -4.08 & 1.268 & 0.179 & 6.432 & 0.064 & -4.37 & 0.892 & 0.463 & 5.913 & 0.821 & -5.74 \\
\hline 20 & 7.339 & 0.034 & 6.768 & 0.026 & -4.59 & 1.439 & 0.036 & 6.912 & 0.057 & -5.67 & 0.933 & 0.111 & 5.959 & 0.057 & -5.84 \\
\hline 60 & 13.455 & 0.032 & 6.848 & 0.025 & -5.28 & 1.466 & 0.034 & 7.210 & 0.055 & -5.87 & 1.795 & 0.178 & 6.119 & 0.408 & -6.0 \\
\hline
\end{tabular}

Table 3. Effect of different uv/ozone treatment times on (K/S, levelness parameters and $\Delta \mathrm{E})$ values of the examined samples dyed with reactive dye

\begin{tabular}{|c|c|c|c|c|c|c|c|c|c|c|c|c|c|c|c|}
\hline \multirow[b]{2}{*}{$\begin{array}{l}\text { exposure } \\
\text { time } \\
\text { minutes }\end{array}$} & \multicolumn{5}{|c|}{ Wool } & \multicolumn{5}{|c|}{ Polyester } & \multicolumn{5}{|c|}{ wool/polyester blend } \\
\hline & $\mathrm{K} / \mathrm{S}$ & $\begin{array}{c}\sum \mathrm{Sr} \\
(\lambda)\end{array}$ & $\mathrm{L}$ & $\mathrm{U}$ & $(\Delta \mathrm{E})^{*}$ & $\mathrm{~K} / \mathrm{S}$ & $\begin{array}{c}\sum \mathrm{Sr} \\
(\lambda)\end{array}$ & $\mathrm{L}$ & $\mathrm{U}$ & $(\Delta \mathrm{E})^{*}$ & $\mathrm{~K} / \mathrm{S}$ & $\begin{array}{c}\sum \mathrm{Sr} \\
(\lambda)\end{array}$ & $\mathrm{L}$ & $\mathrm{U}$ & $(\Delta \mathrm{E})^{*}$ \\
\hline $\begin{array}{c}0 \\
\text { (blank) }\end{array}$ & 2.446 & 0.0362 & 8.252 & 0.009 & $\underline{\mathbf{0}}$ & 0.155 & 0.033 & 5.029 & 0.112 & $\underline{\mathbf{0}}$ & 0.422 & 0.039 & 7.003 & 0.102 & $\underline{\mathbf{0}}$ \\
\hline 1 & 2.853 & 0.0434 & 8.188 & 0.0085 & -0.25 & 0.169 & 0.034 & 5.868 & 0.056 & -0.01 & 0.488 & 0.037 & 6.970 & 0.085 & -3.28 \\
\hline 3 & 3.628 & 0.0452 & 8.213 & 0.008 & -0.71 & 0.169 & 0.033 & 5.937 & 0.053 & -0.19 & 0.493 & 0.034 & 7.086 & 0.020 & -4.42 \\
\hline 5 & 4.566 & 0.0425 & 8.372 & 0.007 & -1.21 & 0.181 & 0.031 & 6.148 & 0.044 & -0.21 & 0.549 & 0.076 & 5.616 & 0.069 & -4.48 \\
\hline 10 & 6.901 & 0.0407 & 8.578 & 0.006 & -1.66 & 0.189 & 0.037 & 6.290 & 0.042 & -0.32 & 0.746 & 0.031 & 7.424 & 0.045 & -5.2 \\
\hline 15 & 10.712 & 0.0427 & 9.537 & 0.003 & -2.21 & 0.283 & 0.033 & 6.426 & 0.039 & -0.65 & 0.777 & 0.033 & 7.377 & 0.016 & -5.58 \\
\hline 20 & 14.609 & 0.0398 & 9.951 & 0.002 & -2.51 & 0.298 & 0.031 & 6.543 & 0.037 & -0.77 & 1.002 & 0.032 & 7.761 & 0.012 & -5.70 \\
\hline 60 & 22.563 & 0.0474 & 10.282 & 0.001 & -2.95 & 0.298 & 0.057 & 6.984 & 0.025 & -0.86 & 2.144 & 0.034 & 8.381 & 0.007 & -5.89 \\
\hline
\end{tabular}




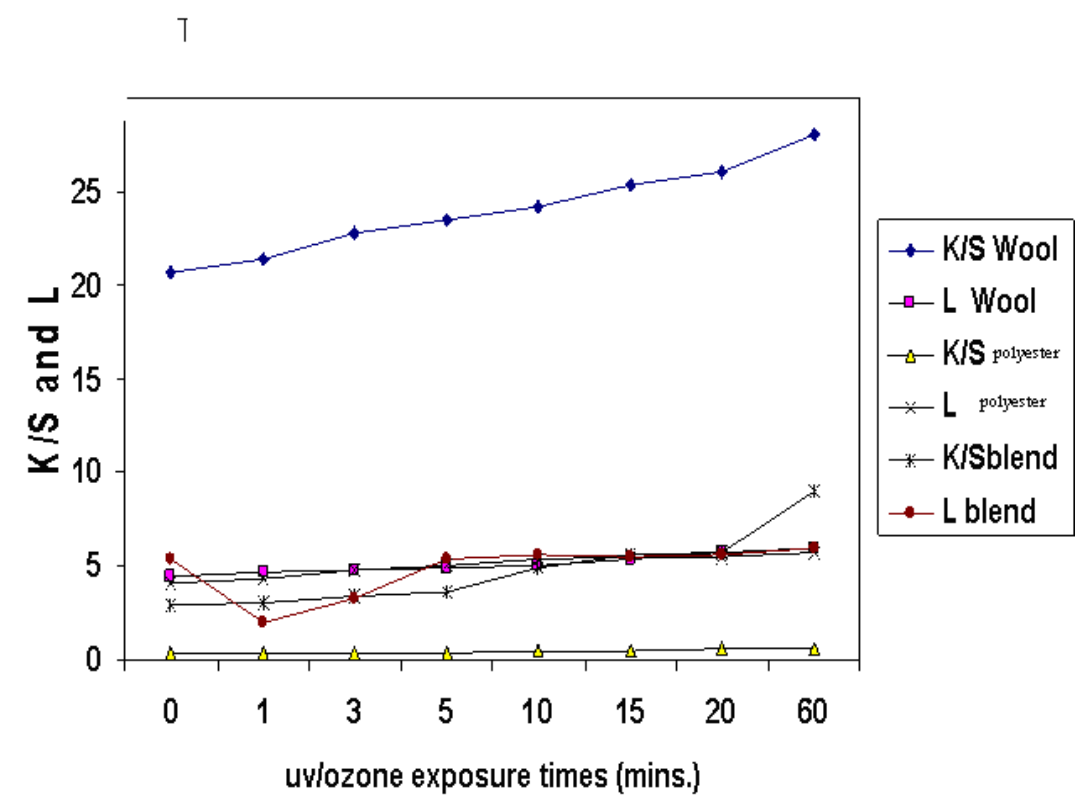

Figure 1. Effect of different uv/ozone treatment times on K/S and levelness parameters values of the examined samples dyed with acid dye

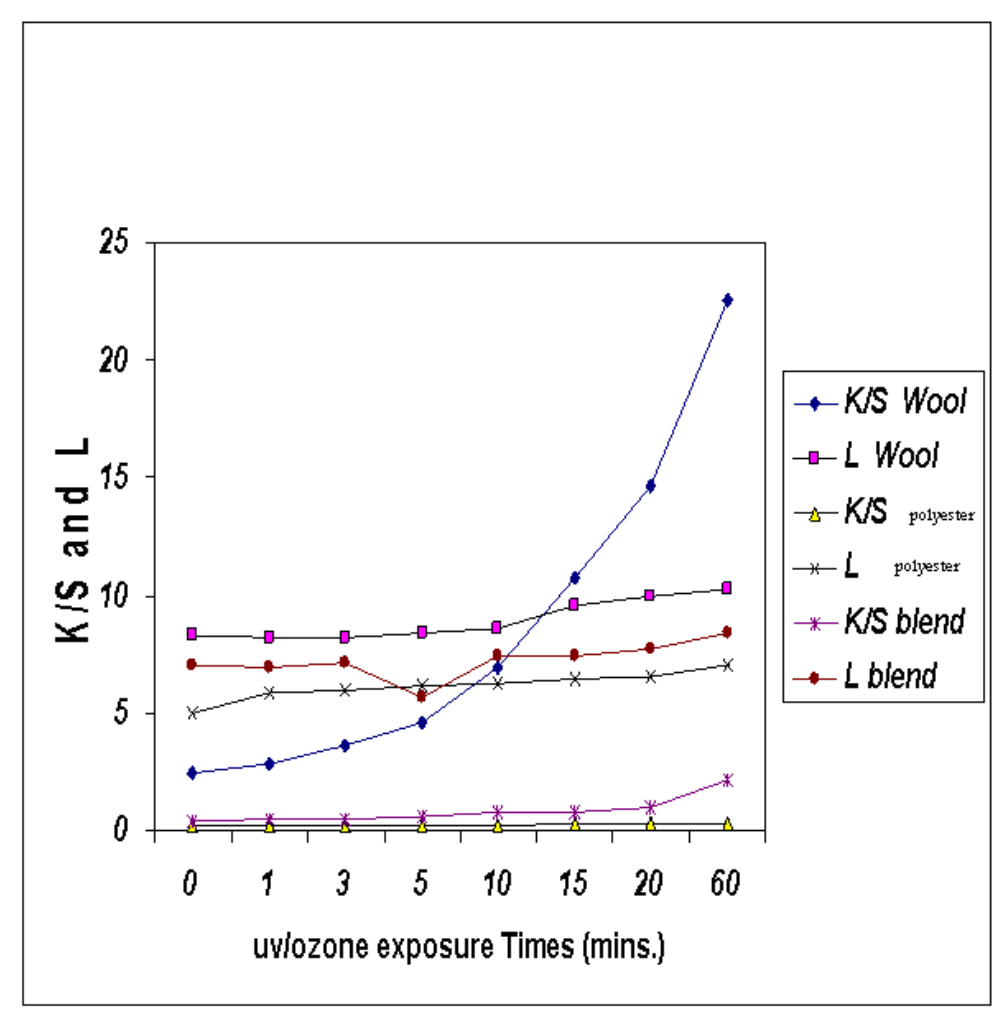

Figure 2. Effect of different uv/ozone treatment times on $\mathrm{K} / \mathrm{S}$ and levelness parameters values of the examined samples dyed with reactive dye 


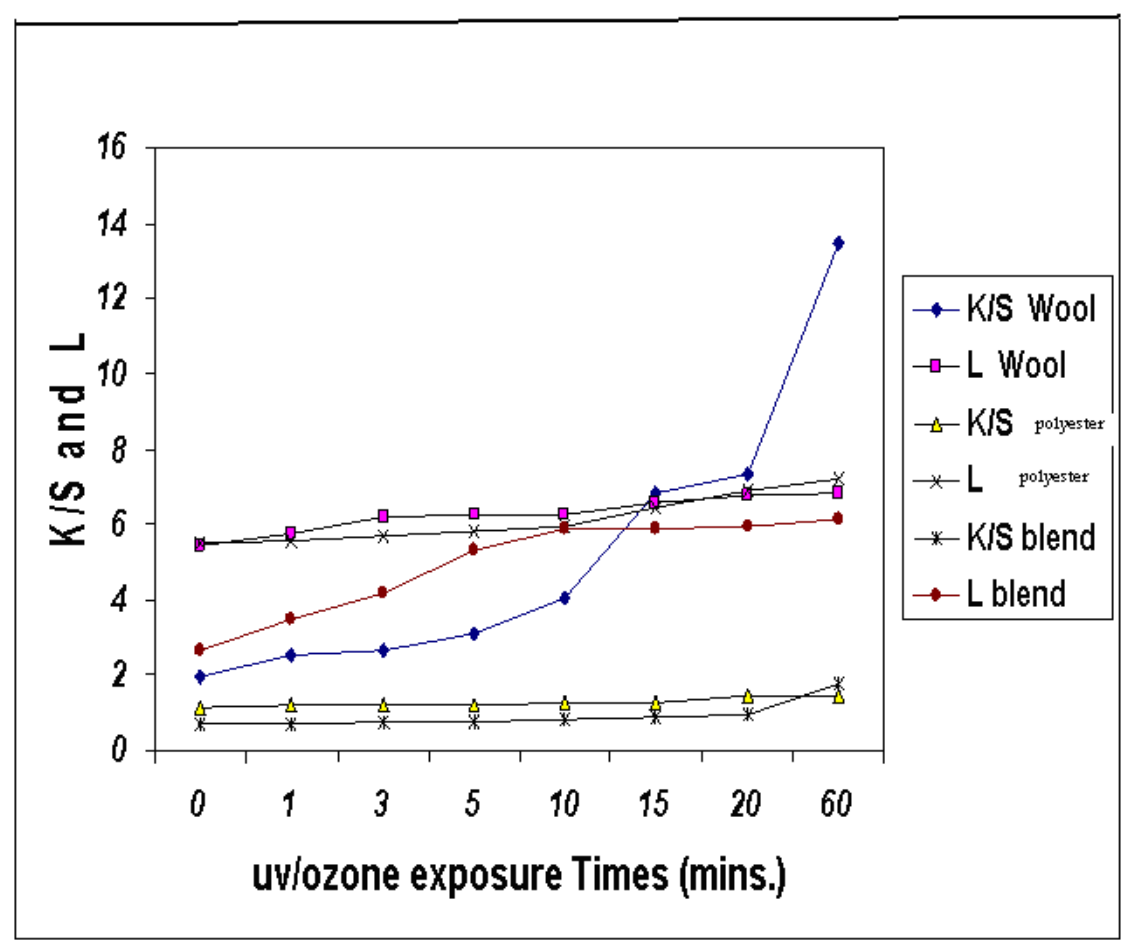

Figure 3. Effect of different uv/ozone treatment times on K/S and levelness parameters values of the examined samples dyed with direct dye

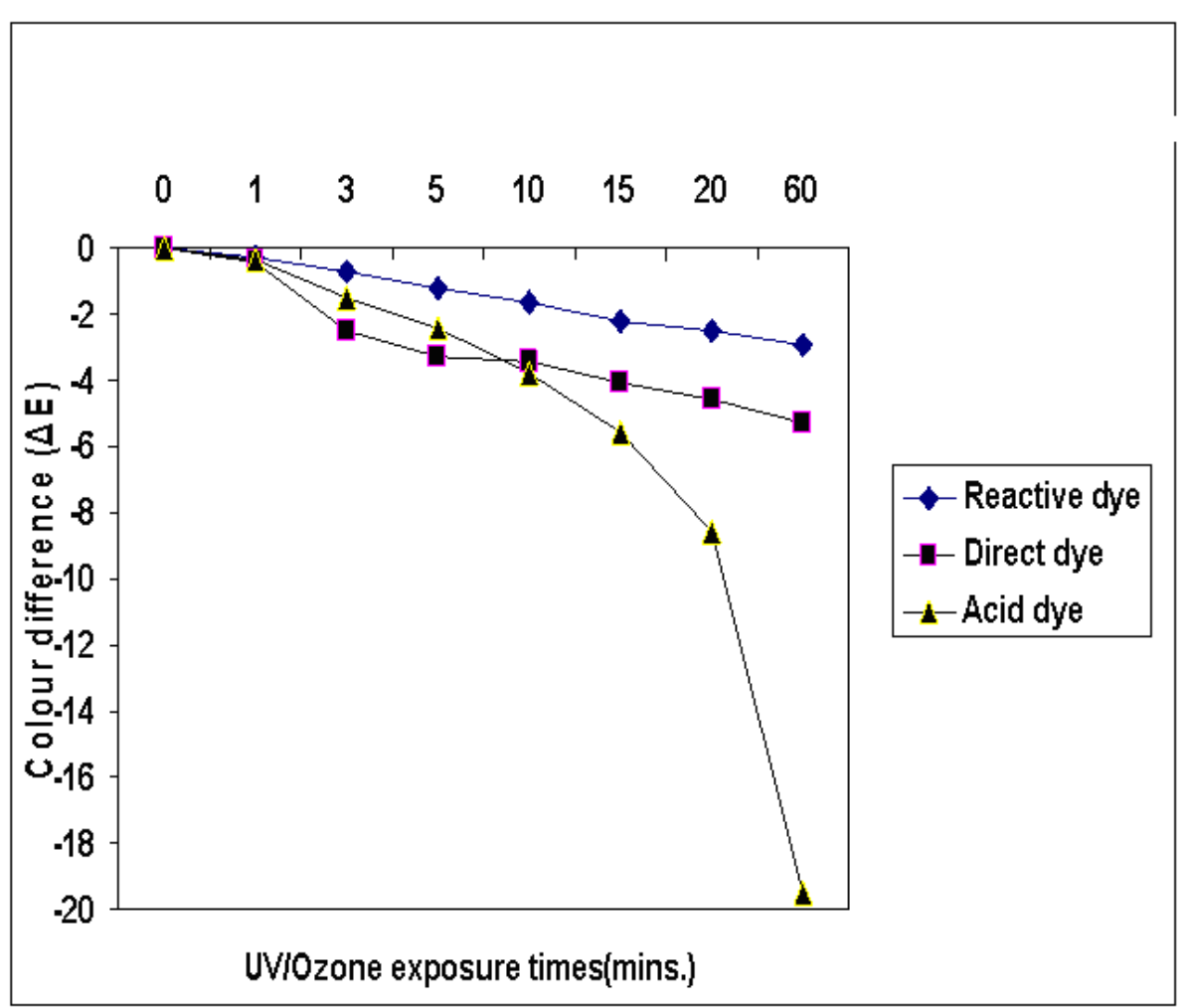

Figure 4. Variation of colour difference $(\Delta \mathrm{E})$ values of the examined wool samples dyed with different dyes at different uv/ozone exposure 


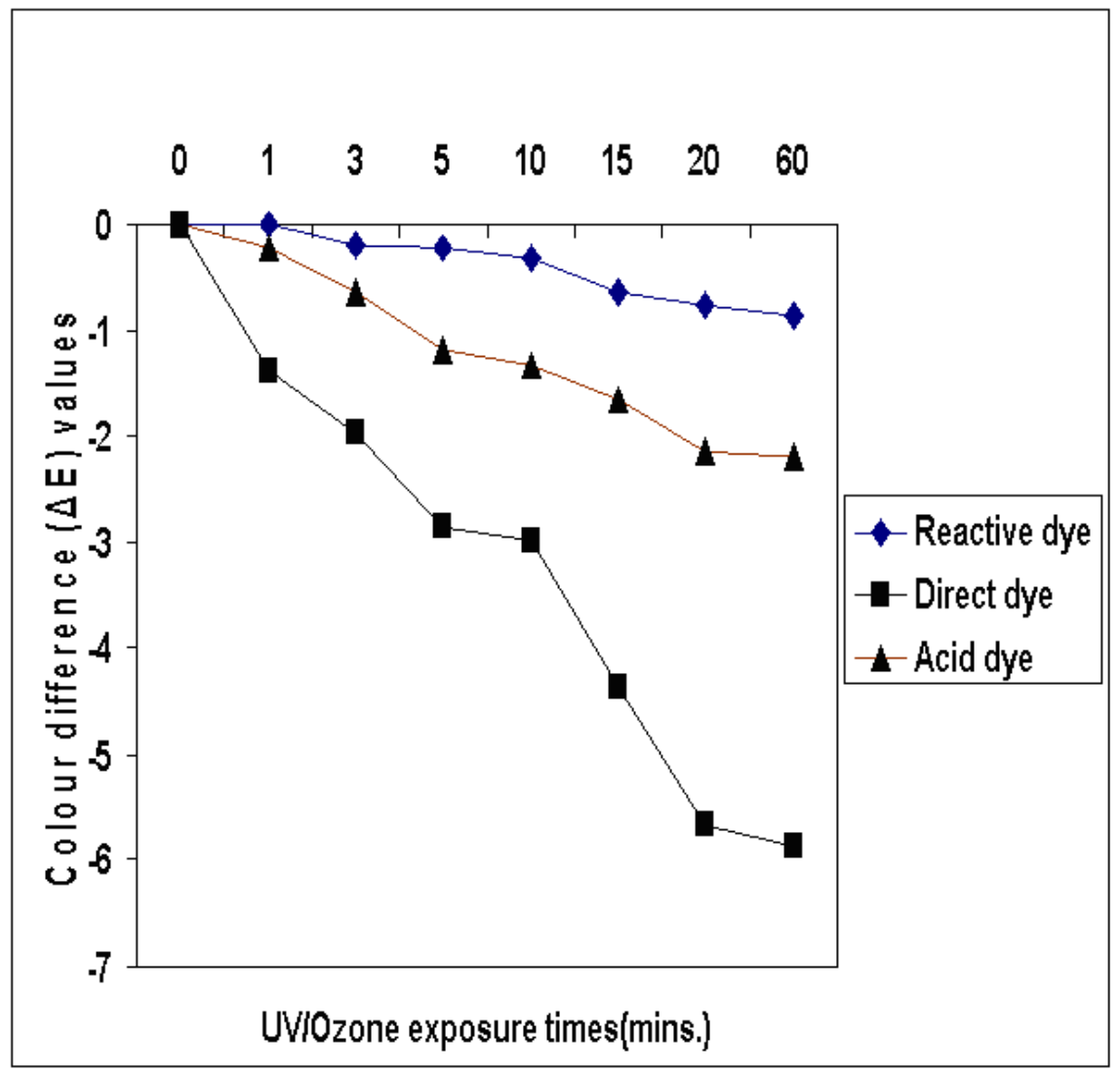

Figure 5. Variation of colour difference $(\Delta \mathrm{E})$ values of the examined polyester samples dyed with different dyes at different uv/ozone exposure

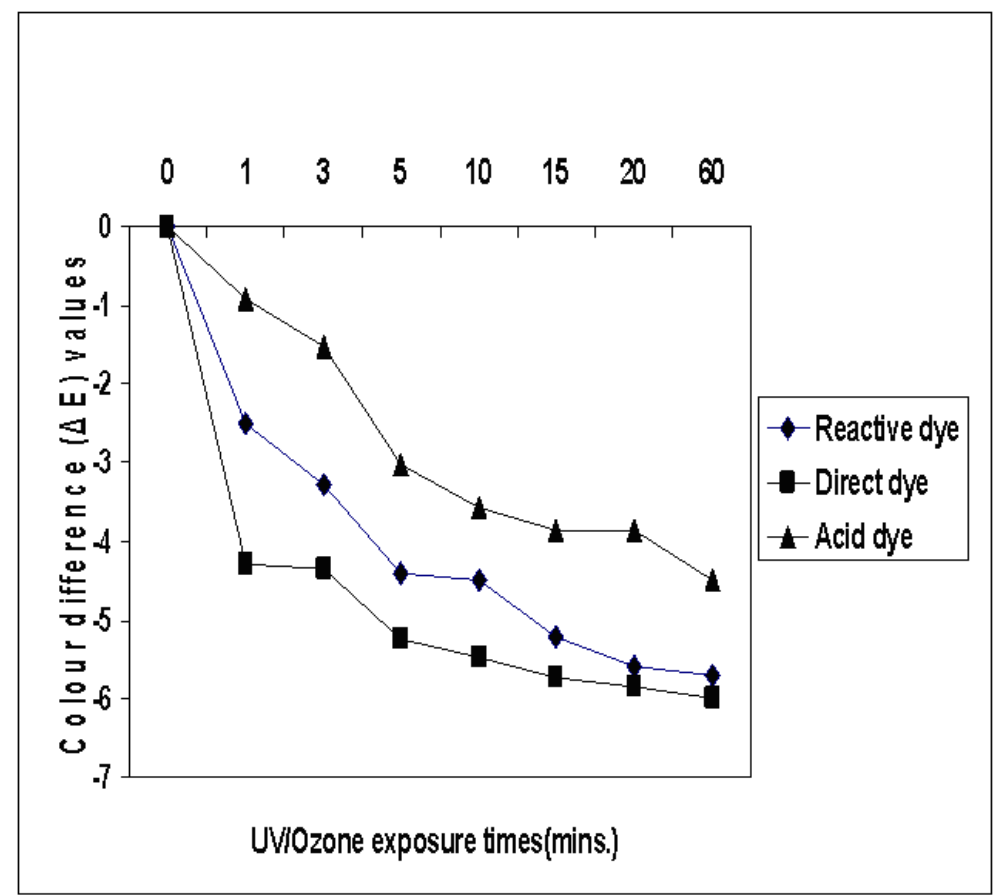

Figure 6. Variation of colour difference $(\Delta \mathrm{E})$ values of blend wool/polyester samples dyed with different dyes at different uv/ozone exposure 